\title{
Gender effects in personality: A Cross-cultural affective neuroscience perspective
}

Özkarar-Gradwohl, F.G.; Turnbull, Oliver H.

\section{Culture and Brain}

DOI:

$10.1007 / \mathrm{s} 40167-021-00099-5$

Published: 01/12/2021

Peer reviewed version

Cyswllt i'r cyhoeddiad / Link to publication

Dyfyniad o'r fersiwn a gyhoeddwyd / Citation for published version (APA):

Özkarar-Gradwohl, F. G., \& Turnbull, O. H. (2021). Gender effects in personality: A Crosscultural affective neuroscience perspective. Culture and Brain, 9, 79-96 . https://doi.org/10.1007/s40167-021-00099-5

\footnotetext{
Hawliau Cyffredinol / General rights

Copyright and moral rights for the publications made accessible in the public portal are retained by the authors and/or other copyright owners and it is a condition of accessing publications that users recognise and abide by the legal requirements associated with these rights.

- Users may download and print one copy of any publication from the public portal for the purpose of private study or research.

- You may not further distribute the material or use it for any profit-making activity or commercial gain

- You may freely distribute the URL identifying the publication in the public portal ?
}

Take down policy

If you believe that this document breaches copyright please contact us providing details, and we will remove access to the work immediately and investigate your claim. 


\title{
Gender Effects in Personality: A Cross-cultural Affective Neuroscience Perspective
}

\author{
Özkarar-Gradwohl, F.G. (1) \& Turnbull, O. H. (2)
}

(1) Çınar Psychotherapy Center, Istanbul, Turkey

(2) School of Psychology, Bangor University, Wales, UK

\begin{abstract}
Despite enormous progress in understanding the neuroscientific elements that underpin the basic emotions, far less attention has been paid to individual differences. The Affective Neuroscience Personality Scales (ANPS) aim to measure these universally-shared subcortical affective systems on which personality is built: CARE, PLAY, SEEK, SADNESS, FEAR and ANGER. Gender differences have been reported in several previous ANPS studies, but no systematic review of these findings has yet been conducted. The present study reviewed ANPS gender effects in 15 countries: (from West to East) Canada, U.S.A., Portugal, Spain, France, Italy, Germany, Norway, Poland, Serbia, Turkey, Russia, China, Hong Kong, and Japan. The total sample size was $\mathrm{N}=6500$, composed of $38 \%$ males and $62 \%$ females. The mean age for the total sample was 26 years. The results showed that gender differences on the ANPS were variable, for different classes of basic emotions. These categories included emotions on which females scored universally higher (CARE and SADNESS); emotions that showed variability based on geography (FEAR and PLAY); and emotions that showed virtually no gender effect (SEEKING and ANGER). These findings can be interpreted in the light of biological universals, geographical variation caused by genetics, and cultural variation in emotion expression and regulation. The results were broadly consistent with gender effects reported in the Big Five personality literature, including a trend of gender differences increasing when moving from 'East' to 'West'. The paper reviews a range of suggestions for future research, including cultural data, genomic data and/or culture-gene interactions.
\end{abstract} Keywords: gender, culture, personality, Affective Neuroscience Personality Scales, Crosscultural affective neuroscience, Big Five, basic emotions 
Feelings are at the centre of the mind, and underpin motivation, adding the mental 'colour' to the objects and choices of our lives. The last few decades have seen enormous gains in our understanding of these feelings, and indeed their biological basis. There is an emerging agreement in the literature that there are a number of basic emotions (broadly speaking 4 to 7 emotions), all mediated primarily by subcortical brain structures (Damasio \& Carvalho, 2013; Eckman, 1992; Panksepp, 1998). Neuroscientifically, these emotion systems are organized in a bottom-up hierarchy, such that the more foundational elements (for example in the upper brain stem) seem dedicated to the core experience of emotion (Panksepp \& Solms, 2012; Panksepp \& Watt, 2011). Higher levels of the system (for example the amygdala) are dedicated to emotional memory. Finally, cortical brain areas, especially the various surfaces of the frontal lobes, seem to be involved in the control and management of emotions (Salas et al., 2014). In line with the literature, affective neuroscience defines the emotions based in these subcortical affective systems as "primary processes," which are shaped by the "secondary processes" of learning and development, which end in cortical cognitive systems as "tertiary processes" (Panksepp, 1998; Panksepp \& Biven, 2012).

Despite enormous progress in understanding the neuroscientific elements that underpin the basic emotions, far less attention has been paid to individual differences in these emotions. This is, potentially, a critically important issue, given that variation in basic emotions may well underpin the central topic of individual differences and gender differences in personality (Montag \& Panksepp, 2017). The Affective Neuroscience Personality Scales (ANPS) enable investigation of this topic, as a psychometric tool for measuring the basic emotions.

\section{The Affective Neuroscience Personality Scales}

Panksepp, the father of Affective Neuroscience, dedicated his life to demonstrating that the foundations of mental life and consciousness lie in the archaic layers of the brain 
(Panksepp, 1998; 2000, Panksepp and Solms, 2012). Viewed in this way, personality develops from the strengths and weaknesses found in the basic affective systems, which are initially regulated by the caregiver-infant attachment style, and other early (and to some extent later) environmental experiences (Davis et al., 2003; Davis \& Panksepp, 2018; Panksepp and Watt, 2011). Based on this bottom-up neurodevelopmental approach, the ANPS was constructed in 2003 (Davis et al., 2003).

The ANPS seeks to measure the subcortical affective systems, which form the foundation of core feelings. This stands in contrast to previous approaches to personality, most notably the "Five Factor Personality" model (Costa and McCrae, 1992). This influential approach, widely used in the twentieth century, lacked a strong evolutionary and neurodevelopmental basis, and is instead built by a lexical approach, based on factor analysis of large samples of questionairre data. The Five Factors are based on a top-down approach, focusing mostly on cognitions, behaviors and executive control over emotions. In contrast, the ANPS aims to measure the universally-shared subcortical affective systems on which personality is built, with categories of question based on a set of neurobiologically derived forms of 'natural kinds', shared by non-linguistic mammal species. This produces a 'bottomup' approach, mapped on to the subcortical affective roots of personality, shaped by the caregiver-child interactions that predate language development (Panksepp, 1998).

The ANPS measures six basic affective systems (always written in uppercase in the affective neuroscience literature): CARE, PLAY, SEEKING, FEAR, SADNESS, and ANGER (Davis et al., 2003). For the three positive affects, CARE is defined as nurturing, feeling soft-hearted toward animals and people in need, feeling empathy, and feeling affection for and liking to care for others", PLAY is described as "having fun, playing games involving physical contact, humor, laughter, and being generally happy and joyful”, SEEKING is 
defined as "feeling curious, feeling like exploring, and striving for solutions to problems" (Davis et al., 2003).

For the three negative affects, SADNESS monitors "feeling lonely, crying frequently, thinking about loved ones and past relationships, and feeling distressed when not with loved ones", FEAR reflects the tendency for "feeling anxious and tense, worrying, struggling with decisions, ruminating about past decisions, losing sleep, and not typically being courageous," and ANGER for "feeling hotheaded, being easily irritated and frustrated, expressing anger verbally/physically, and remaining angry for long periods” (Davis et al., 2003).

The ANPS original version, which was comprised of 110 items, has been revised slightly as ANPS 2.4, with 112 items (Davis \& Panksepp, 2011) and these two forms are referred as the "long versions". The ANPS has been also abbreviated as the Brief ANPS (BANPS) (Barret et al, 2013) and ANPS-S (Pingault et al., 2012), which are named as the "short versions". Orri et al. (2016) has studied the longitudinal invariance and gender measurement invariance for ANPS 2.4 and BANPS. Their results showed that both versions have full longitudinal invariance, suggesting that ANPS measures personality traits that have long-term stability. The findings also showed partial scalar gender invariance for BANPS, and full scalar gender invariance for ANPS 2.4, demonstrating that males and females have a similar understanding of the items. Therefore a statistically significant difference in the mean scores of males and females can be trusted to reveal real gender differences (Orri et al. 2016). Comparing the results of the three versions (ANPS 2.4, ANPS-S, BANPS) applied to the same clinical sample, Geir et al. (2014), found that especially the BANPS did not systematically cover the full theoretical content of the long scales, for CARE and SADNESS. Finally, studies that used the ANPS in clinical populations with dysthymia, anxiety, borderline personality disorder, bipolar disorders, and with adult Autism spectrum conditions (Savitz, Van der Merwe, \& Ramesar, 2008a; J. Savitz, Van Der Merwe, \& Ramesar, 2008b; 
Geier et al., 2014; Carré et al., 2015) also suggested meaningful links between certain subcortical affective systems measured by the ANPS and the specific characteristics of the clinical sample under investigation. These studies demonstrate also the clinical reliability of the ANPS.

Thus far, the ANPS has been translated into several languages: Spanish, French, Turkish, Norvegian, Italian, Polish, Portuguese, Persian, Japanese, Chinese, German, Brazilian Portuguese, Serbian, Russian (Pahlavan et al., 2008; Abella et al., 2011; Pingault et al., 2012; Özkarar- Gradwohl et al., 2014; Geier et al., 2014; Pascazio et al., 2015; Cwojdzińska \& Rybakowski, 2015; De Almeida, 2016; Amiri \& Azad-Marzabadi, 2017; Narita et al., 2017; Sinderman et al., 2018; Reuter et al., 2017; Gurfinkel et al., 2018; Montag et al., 2019; Volf \& Privodnova, personal communication) and has been also standardized for the Hong Kong and Canadian populations (Yu et al., 2016; Orri et al., 2016). All these ANPS standardization studies confirmed the main general findings of the original ANPS study, (Davis et al, 2003) and demonstrated that ANPS is a reliable and a valid tool.

Comparative ANPS studies have been also carried out to observe the influences of rural/urban settings and independent/interdependent cultures on basic affective systems. Sindermann et al. (2017) initiated the discussion that the rural life and the urban life might have different influences on the shaping of basic affective systems, measured by the ANPS. Cultures with varying levels of independency and interdependency were also shown to influence the ANPS findings differently (Özkarar-Gradwohl et al., 2014; Özkarar-Gradwohl et al., 2018). These studies demonstrate that the regulation of basic affects can vary based on the environmental settings of a person and cultural norms.

\section{Gender effects and the Big Five Factors}

Thus far, the literature on gender effects on personality focuses mostly on the Big Five personality factors. These studies have the advantage of large sample sizes, but have (as 
described above) a poor mapping onto evolutionary subcortical affective systems. Notably, the factor analysis basis of the lexically driven Big Five opens the approach to variation based on cultural differences. Especially, the findings that are linked to West-East stereotyping (with Westerners scoring higher on Big Five factors, except Aggreableness) leads to debate regarding the probable low cultural immunity of the approach (McCrae, 2002; Schmitt et al., 2008; Gurven et al., 2013; Özkarar-Gradwohl, 2019).

Big Five cross-cultural meta-analysis points to three major findings. Firstly, females generally have significantly higher levels of Neuroticism (49/55 nations) and Agreeableness (34/55 nations) across most (but not all) nations. In addition, females had significantly higher levels of Extraversion (25/55 nations) and Conscientiousness (23/55 nations) in almost half of the countries (Schmitt et al, 2008). Gender differences in Openness to Experience were more mixed. Generally men scored higher than women in Openness to Experience (37/55 cultures, but only in 8 cultures was this difference statistically significant). In some cultures women's Openness to Experience was higher than men's (18/55 cultures, but only in 4 cultures was this difference statistically significant). Secondly, the national differences in males' scores seemed to be the primary contributor to gender differences in Big Five personality traits across cultures (Schmitt et al, 2008). Thirdly, the gender differences in Big Five personality traits have often been found to be larger in North America, South America, Europe, but narrower in Africa and South/Southeast Asia (Costa et al., 2001; McCrae, 2002; Schmitt et al., 2008). Schmitt et al. (2008) concluded that gender differences on the Big Five appear to diminish as one moves from Western to non-Western cultures.

The relationship between the Big Five and the ANPS subscales has been investigated in almost all ANPS standardization studies (Pahlavan et al., 2008; Abella et al., 2011; Pingault et al., 2012; Özkarar-Gradwohl et al., 2014; Montag et al., 2016a,b; Montag and Davis, 2018). Marengo et al. (in preparation) carried out a meta-analysis on these findings, 
which showed moderate to strong positive correlations between Aggreeableness and high CARE / low ANGER, Neuroticism and SADNESS/ FEAR/ ANGER, Extraversion and PLAY/ SEEKING and finally Openness to Experience and SEEKING. These positive correlations probably point to the subcortical affective roots of the behaviors, cognitions, control over emotions measured by the Big Five factors. They also suggest probable gender effects that can be expected in the ANPS literature. As the most widespread gender effect for the Big Five is higher Agreeableness and Neuroticism in females, higher CARE and negative emotions in females might be also expected for the ANPS.

Regarding the cultural influences of gender effects on personality, Schmitt et al. state that "evolutionary psychologists do not expect evolved gender differences in personality to take precisely the same form and size across all cultures. Indeed, they expect human personality to be highly sensitive to ontogenetic and socioecological contexts, which may affect men's and women's personalities very differently" (2017). With a similar concern about gender effecst on emotions, Chaplin (2015) notes that the gender effect findings on emotions are derived primarily from studies in North America or North Western Europe, and she suggests that these gender effects should be investigated across a wider range of cultures.

Notably, the ANPS literature has a strength in this regard, because it reports the gender effect on personality and emotions, with studies distributed across a wide range of nations. However, no systematic review of all those gender effect findings on the ANPS has yet been conducted. The present review aims to survey the gender effects in all existing ANPS studies, in order to clarify the gender findings in basic emotions, as well as investigating any geographical variability.

\section{Review Method}

In order to review the gender effects in cross-cultural affective neuroscience, a literature search was conducted to find all the available published papers that utilized the 
ANPS, until May 2020. Initially, all papers that employed the ANPS were identified using the keyword "affective neuroscience personality scale/s". Secondly, these articles were checked to establish the tabulated sample sizes, ANPS means and standard deviations for males and females. 11 studies had tabulated this information, and were included in the review directly. 9 papers did not tabulate their results separately for gender, therefore the corresponding author was contacted in order to ask for the tables regarding gender differences. 5 did not reply and 1 no longer had access to the data. The remaining 3 provided the requested data and these were added to the sample (Portugal, Serbia, Hong Kong). One final paper (from Russia) is in preparation and the data were asked from the authors via personal communication. Finally, if more than one paper was published in a country, the choice of the article for that country was made in the favor of the paper, which had already presented a gender differences table. Also, in order to standardize the scalar gender invariance and content validity, the papers that utilized the longer versions (ANPS original and ANPS 2.4) were preferred rather than the shorter versions (ANPS-S and BANPS). When an overlap between samples was found in two articles, the earliest study was selected. Using this approach, only one paper from each country was included in our review, and multiple appearances of any nation in the Table was avoided.

At the end of this stepwise approach, 15 studies from 15 countries were included in our review Table, which is organized vertically from West to East (Canada to Japan). Emotions are presented horizontally, from the largest to the smallest effect size (CARE to ANGER). The Table summarizes the references, versions, sample sizes, age means, ANPS means and standard deviations, for each gender, together with t-test or ANOVA results and $p$ values (see Table 1).

The total sample size was precisely $\mathrm{N}=6500$, ranging from 81 (Cwojdzińska \& Rybakowski, 2015) to 830 (Pingault et al. 2012). The total sample was composed of $37.5 \%$ 
males $(\mathrm{N}=2440)$ and $62.5 \%$ females $(\mathrm{N}=4060)$. The mean age of the samples ranged from 19.3 (Yu et al., 2016) to 39.8 (Volf \& Privodnova, personal communication), with an average age of 25.7 for the total sample. Included studies were from North America ( $\mathrm{n}=2$; Canada \& U.S.A.), Europe (n=9; Spain, Portugal, France, Italy, Germany, Norway, Poland, Serbia, Russia), and Asia (n=4; Turkey, Hong Kong, China, Japan). Among these studies, 7 used the original ANPS version (Davis et al., 2003), 7 used the ANPS 2.4 version (Davis \& Panksepp, 2011), and the ANPS-S was used only once (Pingault et al., 2012). The vast majority of samples were recruited among the general population $(n=14)$, while only one sample was from a clinical population (Geier et al., 2014).

Importantly, different studies employed a range of Likert scales (from 0-3 to 1-6). We report the scores as recorded in the original papers. In all countries, subscale scores were calculated using the same technique for the ANPS original and the ANPS 2.4, based on 14 items for each subscale ( 7 normal and 7 reversed items). The resulting scores ranged between 15-31 for the studies who used the 0-3 Likert scale, and from 34-44 for those who used the 14 Likert scale. In Portugal, the ANPS-S was used, based on a 1-6 Likert scale, and the average subscale scores were calculated from 6 items for each subscale (ranging from 2.74 to 4.71). These variations in scoring methods have no effect on the statistical magnitude of the gender differences.

\section{Results}

For CARE and SADNESS there were highly significant gender effects for most of the countries, all favouring higher scores for females. In 13 countries, females scored significantly higher than males on CARE (ranging from $\mathrm{p}<.001$ to $\mathrm{p}<.0001$, except Portugal with $\mathrm{p}<.05$ ). The exceptions were Japan (significant in the direction of males) and China (no significant effect). In 12 countries females scored significantly higher on SADNESS (ranging from $\mathrm{p}<.05$ to $\mathrm{p}<.0001$ ). Exceptions were again Japan (significant in the direction of males), 
and Hong Kong (no significant effect). For FEAR, in 9 countries out of 15, females scored significantly higher (ranging from $\mathrm{p}<.05$ to $\mathrm{p}<.0001$ ). Yet again the exception was Japan (significant in the direction of males), and also Turkey, Hong Kong, China and Serbia (no significant effect).

Gender effects for PLAY were small in size and more mixed between genders. There were significantly higher PLAY scores in males in five countries, namely Portugal, France, Canada, Italy and China (ranging from $\mathrm{p}<.01$ to $\mathrm{p}<.05$ ). There were significantly higher scores for females in two countries, namely Turkey and Hong Kong (both $\mathrm{p}<.05$ ) and no significant effect in seven countries. Finally, most countries did not show a significant gender effect on SEEKing and ANGER. 13 out of 15 countries showed no significant gender effect on SEEKing. Only exceptions were males scoring significantly higher in U.S. $(p<.1)$ and females scoring significantly higher in Spain $(\mathrm{p}<.005) .13$ out of 15 countries showed no significant gender effect on ANGER, with Canada and Portugal being the only exception where females scored significantly higher than males $(\mathrm{p}<.05$ and $\mathrm{p}<.0001)$.

A second way of analysing the data is through the lens of geographic and cultural diversity. When the total number of significant results, across all emotions $(n=48)$, were analyzed by continental groups, there is a broad trend of the number of significant results decreasing when moving from 'West' to 'East'. North America had the highest ratio of significant gender effects ( 8 significant differences across 2 countries: Ratio 4). Europe had the second highest ratio of significant results (30 significant differences/9 countries: Ratio 3.3). Asia showed the lowest ratio of significant gender effects ( 10 significant differences/4 countries: Ratio 2.5).

There were three notable differences between the notionally 'Western' and 'Eastern' samples. Firstly; the gender effects in North America and Europe seemed more homogeneous, with a shared gender effect: where females had higher CARE, SADNESS and FEAR scores in 
almost all countries. In contrast, the gender effects in Asia were more heterogeneous, and there was no clear within-continent gender effect. Secondly; the clearest difference across continents was the absence of higher FEAR in females in Asia. Out of 10 total significant differences in FEAR, 9 were from North America and Europe, where females scored significantly higher than their male counterparts. In Asia, the only significant difference in FEAR was in Japan, but in the 'male-higher' direction. In short, the trend, from East to West, was for females to have higher FEAR than their male counterparts. Thirdly, out of 7 significant differences in PLAY, 4 out of 10 Western countries showed higher PLAY in the male direction, while 2 out of 4 Eastern countries showed higher PLAY in the female direction (with the exception of China having higher PLAY in males).

\section{Discussion}

The results of this literature review showed that the gender differences on the ANPS were variable for different classes of basic emotions. Our findings included some emotions on which females scored universally higher, some emotions that showed variability based on geography, and some emotions that showed virtually no gender effect.

\section{Virtually Universal Gender Effects:}

Regarding the first class of emotions, the results showed the most widespread gender effects for CARE and SADNESS. Here females showed significantly higher scores compared to their male counterparts in almost all countries. In other words, females of almost all nations reported scores suggesting higher levels of caring, nurturing and empathy. On average, they feel more distressed and lonely when separated from their loved ones, in comparison to males. This common gender effect points to a greater female 'resonance' with items linked to attachment (CARE) and separation distress (SADNESS).

This is also consistent with the affective neuroscience literature suggesting that female mammals show more behaviors linked to attachment and separation distress, and greater 
activation in the anterior cingulate gyrus (Panksepp, 1998; 2012). Higher levels of the attachment neuropeptide oxytocin, and lower rates of serotonin synthesis found in females seem to function as some of the neurobiological mechanisms underlying these higher CARE and SADNESS scores (Nishizawa et al., 1997; Panksepp, 1998, 2012). These findings are also in line with the widely accepted gender identity formation theory (Chodorow, 1994; Hartwell et al., 1992; Kağıtçıbaşı, 2005) that women build their identities on relatedness, and men on separateness. On the other hand, the absence of higher CARE and SADNESS scores in the females of China and Japan needs to be investigated further, to see whether the collectivistic culture effect, that reinforces relatedness and discourage separateness (Kağıtçıbaşı, 2005; 2007), may influence this virtually 'universal' gender effect (ÖzkararGradwohl, 2019).

Finally, this almost universal gender effect on the ANPS, of higher CARE and SADNESS scores in females, corresponds to the most widespread gender effect on the Big Five, corresponding to higher Agreeableness and Neuroticism scores in females (Schmitt et al., 2008). The Big Five and ANPS correlations show that Agreeableness is positively correlated with CARE, and Neuroticism with the negative basic affects measured by the ANPS (Montag \& Davis, 2018; Marengo et al., in preparation). These correlations indicate that the Big Five dimensions of Agreeableness and Neuroticism might be subcortically rooted into CARE and SADNESS systems, which seem to be more activated in females internationally.

\section{Geographical Gender Effects:}

The findings of the present review also reached to a second class of emotions, namely FEAR and PLAY, that showed gender effect variability based on geography. While most females in North America and Europe had higher FEAR scores than their male counterparts (in 9 countries out of 11), the total absence of higher average FEAR scores in Asian females 
was remarkable. In other words, while on average most Western females seemed to feel more anxious, tense, worried, indecisive and less courageous than their male counterparts, most Asian females and males had similar levels of anxiety. How the collectivistic culture effect (emphasizing relatedness) and individualistic culture effect (emphasizing separateness and autonomy) might regulate the experience of anxiety (FEAR) needs to be explored further.

The well-known cross-cultural finding that the West, despite its higher report of subjective well-being, has a higher prevalance of mood and anxiety disorders compared to the East (De Vaus et al., 2017) has caused several different discussions in the literature. One line of argument suggests that Western individualism causes loneliness, isolation and lower social support, which in turn leads to higher anxiety. An alternative perspective is that Eastern holistic thinking helps people to accept all emotions, including the negative ones, which in turn leads to better coping with anxiety (Chen, 1996; De Vaus et al., 2017). However, neither of these arguments have ever been linked to neurobiological evidence. Current cross-cultural neuroscience supplies the empirical evidence that there is an association between collectivistic cultural values and short allelic frequency of the serotonin transporter polymorphism (Chiao \& Blizinsky, 2010), and A allelic frequency of the oxytocin receptor gene polymorphism (Luo $\&$ Han, 2014). Thus, the serotonergic and oxytocinergic systems, which are related to anxiety and mood disorders, appear to be mediated by collectivistic cultural values, resulting in a lower prevalance of mood and anxiety disorders (Chiao \& Blizinsky, 2010; Luo \& Han, 2014).

Future studies are required to clarify how culture effects, and genetic effects interact to produce these anxiety level differences between East and West. Genomic data suggests that the migration and admixture of populations (starting in Africa 300000 years ago and moving to Asia, the Middle East, Europe and lastly the Americas some 20000 years ago) have played a large part in generating cultural and genetic diversity (Nielson et al., 2017). Current studies 
on immigration also discuss the negative influence of separation anxiety on immigrants (Van Ecke, 2005). How certain geographies are genetically more vulnerable to anxiety might also be related to culture-gene coevolution during the historical migration of people, where different levels of separation anxiety may have been transmitted across generations.

On the other hand, for the PLAY subscale the findings show more complicated variations across different nations. While 4 out of 10 Western countries showed significantly higher PLAY scores in the male direction, 2 out of 4 Eastern countries showed significantly higher PLAYscores in the female direction. Although this might be discussed as a modest trend for higher PLAYscores in Western males, in contrast to higher PLAYscores in Eastern females, evidence based on these sample sizes are not sufficient for such generalizations. The higher PLAY scores in Chinese males also contradicts such an overgeneralized trend. Therefore, it can be only said that cultures vary in terms of which gender is more 'playful' and that the underlying reasons need to be analyzed further.

Another way of analyzing this cross-cultural variation on the gender effect for PLAY is to observe how PLAY is connected to other basic emotions in different cultures. In other words, which other emotions co-exist with playful experiences, like being generally happy, joyful and humorous, having fun, laughing, and playing games involving physical contact. Although gender specific intercorrelations are mostly unavailable in the literature, the intercorrelations of the ANPS subscales with total samples can provide us with a general picture. It has been repeatedly shown that PLAY is positively correlated with the other two positive emotions, namely CARE and SEEKing in most countries, such as (in order of publication) U.S.A, Spain, France, Turkey, Portugal, Italy, Japan, Iran, Serbia, Austria (Davis et al., 2003; Abella, 2011; Pingault et al., 2012; Özkarar-Gradwohl et al., 2014; De Almeida, 2016; Giacolini, 2017; Narita et al., 2017; Amiri, 2017; Hiebler-Ragger, 2018; Montag et al. 2019). Therefore, for almost all cultures, playfulness is a social interaction style with the ones 
whom we CARE and SEEK for, and we feel happier and more joyful when surrounded by them.

In contrast, the intercorrelations of PLAY with negative emotions show more variance across countries. These intercorrelations vary between a negative correlation with all three negative emotions, namely SADNESS, FEAR and ANGER (in Portugal), negative correlation with only SADNESS and FEAR (e.g. France, Norway, Turkey, Italy, Japan, Serbia), no correlation at all with negative emotions (e.g. in U.S.A.), and positive correlation with FEAR (e.g. in Spain, Iran, Austria). These findings suggest that in different cultures, a different set of negative emotion/s may lead us to withdraw from or engage in being playful with those close to us. Only in the U.S.A. does feeling playful and joyful seem to be disconnected from the presence of negative emotions. However, again, more detailed investigations, with larger sample sizes and gender specific intercorrelations, are required to clarify the influences of culture and of gender on the PLAY system.

\section{Virtually Universal Gender Similarities:}

In the final class, there were two basic emotions for which there were no notable gender effects, namely SEEKING and ANGER. In relation to SEEKING, there was almost no significant gender effect, with only one example from the U.S.A., where males had slightly higher SEEKING scores, and one example from Spain where females had higher SEEKING scores. Besides these two, 13 out of 15 countries showed a gender equivalence in terms of SEEKING. Females and males did not differ from each other in terms of their levels of feeling curious, enjoying exploration and striving for solutions to problems etc.

Panksepp describes the SEEKING system as a passageway from homeostasis to emotion: whatever a mammalian needs in order to restore its homeostasis (e.g. food, water, safety, play, care, lust, information etc.), it turns its attention to the outer world and seeks for this need (Panksepp \& Watt, 2011; Watt, 2017). This is usually regarded as the most 
fundemantal of the basic emotions, and gender differences in mammal species are not reported for this system. It is not clear what causes the occasional gender differences in the samples reported above, such as the U.S.A. and Spain. In addition, it must be noted that the literature on the neurobiology of gender differences on SEEKING related dopaminergic system is underexplored. However, there are studies showing that the dopaminergic reward system of females is more sensitive to prosocial (shared) rather than selfish rewards, whereas the opposite is true for males (Soutschek et al., 2017). Therefore, it might be better to explore the gender differences in the styles of SEEKing (socially related style vs autonomous style), rather than the levels of SEEKing scores.

The second observed gender similarity was a surprising finding for ANGER, with no significant gender effect on ANGER (13/15 countries), except the higher ANGER scores for females in Canada and Portugal. How might one explain the paradox of no gender effect in reported ANGER, but higher violent behaviors in males frequently cited in the criminology or the affective neuroscience literature? (Volavka, 1995; Panksepp, 1998, 2012; Solms and Turnbull, 2002). A meta-analysis of sex differences in agression (Archer, 2004) shows no gender difference for verbal aggression, but large gender differences for physical aggression, in the male direction (Archer, 2004). As the ANGER items on the ANPS do not focus on physical agression but on the level of experienced anger, the absence of a gender effect is actually in line with the general literature on anger.

Males and females can experience similar levels of anger, which appear to result from testesterone derived offensive anger or oxytocin derived defensive anger (Panksepp, 1998; Bosch et al., 2005). However, violent agressive behavior seems to have a more complicated neural basis. The expression of testosterone receptors in the male brain begins in embryonic life, by the seventh to eighth week of pregnancy. Increasing testosterone levels in the fetus induces anatomical changes, that lead to the sexual differentiation of the male brain, for 
example in the amygdala (Panksepp, 1998; Solms \& Turnbull, 2002). Studies on violent behavior show that the level of violence increases as the level of basal testosterone increases. Lower tryptophan hydroxylase in males, which catalyzes serotonin, is also associated with lower control over impulsive agression (Volavka, 1995). Clearly, it will be interesting to link these neurobiological findings to individual differences in experienced and expressed anger.

Moreover, ANGER seems to function differently to other negative emotions, in terms of its relation to attachment and separation systems. While ANGER typically functions in the service of separation, FEAR and SADNESS function to avoid the separation risk, and for mourning after a separation. Although the most widespread gender effect on the Big Five is higher Neuroticism in females (49/55 countries), and although the correlations between the Big Five and the ANPS indicate a positive correlation between Neuroticism and all negative emotions, ANGER is the negative emotion that correlates the least with Neuroticism (Marengo et al., in preparation). Thus, the gender effect results for ANPS deviate from those of the Big Five in the absence of a gender effect on ANGER. It may be that females and males experience the same levels of ANGER during disputes, that lead to the feeling of separateness. However, (as discussed above) the females suffer more from anxiety and depression in relation to separation relevant situations.

\section{Conclusion}

The question of gender differences in personality has been investigated for many decades, particularly in the Big Five literature, and has produced several reliable findings. The ANPS approach offers the possibility to bridge these findings to neurobiology. Gender effect findings of the present cross-cultural ANPS review are mostly consistent with the gender effect findings of the Big Five literature (Costa et al., 2001; Schmitt et al., 2008, 2017). Firstly, the most universal gender effects are higher CARE, and SADNESS scores in females, which correspond to higher Agreeableness and Neuroticism in females, measured by the Big 
Five. Higher FEAR scores in females, in Western countries, is also consistent with the higher Neuroticism scores in females.

Secondly, in line with the Big Five literature, a broad trend of gender differences increasing when moving from 'East' to 'West' is also observed in the present ANPS review. For this trend, it had been argued that 'natural' (neurobiologically derived?) personality traits of males and females might be less constrained in gender egalitarian nations, which provide equal access to education and economic wealth (Costa et al., 2001; Schmitt et al., 2017). Neurodevelopmental research demonstrates that self-development is neuropsychologically shaped by the nature-nurture interaction, mostly within the first six years of life, before the start of formal education, or work (Schore, 1994; Solms \& Turnbull, 2002). The reasons for the Westward increase in gender differences on personality can be also explored by the help of cultural data, genomic data and/or culture-gene interactions.

The link between neurobiology and individual differences is entering a phase of enourmous potential. In this context, the ANPS seems to be a promising neurodevelopmental tool, to observe the influence of nature-nurture interactions on personality traits. The present cross-cultural affective neuroscience review is the beginning of the investigation of the interaction of gender effects and culture effects on affective personality profiles. These future studies of personality may focus more on the influence of biological universals, geographical variation caused by biology, and culture.

\section{References}

Abella, V., Panksepp, J., Manga, D., Bárcena, C., and Iglesias, J. A. (2011). Spanish validation of the affective neuroscience personality scales. Span. J. Psychol. 14, 926-935. doi: 10.5209/rev_SJOP.2011.v14.n2.38

Amiri, S. \& Azad-Marzabadi, E. (2017). Validation of Brief Affective Neuroscience Personality Scales in normal populations. Neuropsychiatria i Neuropsychologia. 12 (3), 95- 
100. doi: $10.5114 /$ nan.2017.71665

Archer J. (2004). Sex differences in aggression in real-world settings: A meta-analytic review. Review of General Psychology, 8, 291-322.

Barrett, F. S., Robins, R. W., \& Janata, P. (2013). A brief form of the Affective Neuroscience Personality Scales. Psychological Assessment, 25(3), 826-843.

https://doi.org/10.1037/a0032576

Bechara, A., Damasio, A.R., Damasio, H. \& Anderson, S.W. (1994). Insensitivity to future consequences following damage to human prefrontal cortex. Cognition, 50, 7-15.

Bosch, O. J., Meddle, S. L., Beiderbeck, D. I., Douglas, A. J., \& Neumann, I. D. (2005). Brain oxytocin correlates with maternal aggression: link to anxiety. The Journal of Neuroscience: the official journal of the Society for Neuroscience, 25(29), 6807-6815.

https://doi.org/10.1523/JNEUROSCI.1342-05.2005

Carré, A., Chevallier, C., Robel, L., Barry, C., Maria, A.S., Pouga, L., Philippe, A., Pinabel, F., \& Berthoz, S. (2015). Tracking Social Motivation Systems Deficits: The Affective Neuroscience View of Autism. Journal of Autism and Developmental Disorders, 45(10), doi: 10.1007/s10803-015-2498-2

Chaplin, T. M. (2015). Gender and Emotion Expression: A Developmental Contextual Perspective. Emotion Review: J of the International Society for Research on Emotion, 7 (1), 14-21. doi: 10.1177/1754073914544408

Chen, C.N. (1996). Anxiety and Depresion: East and West. Int Medical Journal, 3(1), 3-5. Chiao, J. Y., \& Blizinsky, K. D. (2010). Culture-gene coevolution of individualismcollectivism and the serotonin transporter gene. Proceedings of the Royal Society Biological Sciences, 277, 529-537.

Chodorow, N. (1994). "Feminism and psychoanalytic theory" in Feminisms. eds. S. Kemp, and J. Squires (Oxford: Oxford University Press), 182-188.

Costa, P. T., \& McCrae, R. R. (1992). The five-factor model of personality and its relevance to personality disorders. Journal of Personality Disorders, 6(4), 343-359. 
https://doi.org/10.1521/pedi.1992.6.4.343

Costa, P. J., Terracciano, A., \& McCrae, R. R. (2001). Gender differences in personality traits across cultures: Robust and surprising findings. Journal of Personality and Social Psychology, 81(2), 322-331. http://doi.org/10.1037/0022-3514.81.2.322

Cwojdzińska, A. \& Rybakowski, F. (2015). Operationalization of Jaak Panksepp's concept of brain emotional systems - Affective Neuroscience Personality Scales. Neuropsychiatria i Neuropsychologia 2015, 10 (3-4), 102-109.

Davis, K. L., Panksepp, J., and Normansell, L. (2003). The affective neuroscience personality scales: normative data and implications. Neuropsychoanalysis 5, 57-69. doi:

$10.1080 / 15294145.2003 .10773410$

Davis, K. L. \& Panksepp, J. (2011). The brain's emotional foundations of human personality and the affective neuroscience personality scales. Neuroscience and Biobehavioral Reviews, 35, 1946-1958.

Davis, K. L. \& Panksepp, J. (2018). The emotional foundations of personality: A neurobiological and evolutionary approach. New York, NY: WW Norton \& Company Damasio, A. (2010). Self comes to mind: Constructing the conscious brain. Vintage. Damasio, A., \& Carvalho, G. B. (2013). The nature of feelings: evolutionary and neurobiological origins. Nature reviews neuroscience, 14(2), 143.

De Almeida, M. T. S. F. (2016). Testing the Portuguese version of ANPS-s and its utility for professional selection processes. (Unpublished Master's Thesis). Available from the ISCTEUniversity Institute of Lisbon. (JEL Codes: M12, L84)

De Vaus, J., Hornsey, M.J., Kuppens, P. \& Bastian, B. (2017). Exploring the East-West Divide in Prevalence of Affective Disorder: A Case for Cultural Differences in Coping with Negative Emotion. Personality and Social Psychology Review. 22(3), 285-304. doi:10.1177/1088868317736222

Eckman, P. (1992). Are there basic emotions? Psychological Review, 99(3), 550-553. 
Geir, P., Selsbakk, J. M., Theresa, W., \& Sigmund, K. (2014). Testing Different Versions of the Affective Neuroscience Personality Scales in a Clinical Sample. PLoS ONE, 9(10). http://doi.org/10.1371/journal.pone.0109394

Giacolini, T., Ardizzone, I., Davis, K. L., Ferrara, M., Picconi, L., Terrinoni, A., Sabatello, U. (2017). Brain Emotional Systems: the Italian version of the ANPS - Affective Neuroscience Personality Scales 2.4. Clinical Neuropsychiatry, 14 (4), 263-274.

Gurfinkel, Y., Mileo, R. A., Da Fonseca, M. S. M., \& Esposito, S. B. (2018). Translation of the Affective Neuroscience Personality Scales - Brief to Portuguese and transcultural adaptation. Rev Fac Ciênc Méd Sorocaba, 20(4), 223-9. doi: 10.23925/1984$4840.2018 \mathrm{v} 20 \mathrm{i} 4 \mathrm{a} 8$

Gurven, M., Rueden, C. von, Massenkoff, M., Kaplan, H., \& Vie, M. L. (2013). How universal is the big five? Testing the five-factor model of personality variation among foragerfarmers in the Bolivian Amazon. J of Personality and Social Psychology, 104(2), 354-370. Hartwell, S., Pace, R.C., \& Hutak, R. (1992). Women Negotiating: Assertiveness and Relatedness. In Constructing and Reconstructing Gender: The Links Among Communication, Language and Gender (Ed.s Linda A.M. Perry, Lynn H. Turner, Helen M. Sterk). State University of New York Press, Albany.

Hiebler-Ragger, M., Fuchshuber, J., Dröscher, H. B., Vajda, C., Fink, A., \& Unterrainer, H. F. (2018). Personality Influences the Relationship between Primary Emotions and Religious/ Spiritual Well-Being. Frontiers in Psychology, 9, 370. doi: 10.3389/fpsyg.2018.00370. Kağıtçıbaşı, Ç. (2005). Autonomy and Relatedness in Cultural Context: Implications for Self and Family. Journal of Cross-Cultural Psychology, 36(4), 403-422.

Kağıtçıbaşı, Ç. (2007). Family, Self, and Human Development Across Cultures: Theory and applications (2nd ed.). Mahwah, N.J: L. Erlbaum Associates. 
Luo, S., \& Han, S. (2014). The association between an oxytocin receptor gene polymorphism and cultural orientations. Culture and Brain, 2(1), 89-107.

Marengo, D., Davis, K. L., Özkarar-Gradwohl, F.G., \& Montag, C. (in preparation). A metaanalysis of associations between individual differences in primary emotional systems as assessed with the Affective Neuroscience Personality Scales and Big Five Personality Traits. McCrae, R. R. (2002). Cross-Cultural Research on the Five-Factor Model of Personality. Online Readings in Psychology and Culture, 4 (4). https://doi.org/10.9707/2307-0919.1038 Montag, C., Hahn, E., Reuter, M., Spinath, F. M., Davis, K., and Panksepp, J. (2016a). The role of nature and nurture for individual differences in primary emotional systems: evidence from a twin study. PLoS One 11:e0151405. doi: 10.1371/journal.pone.0151405

Montag, C., Widenhorn-Müller, K., Panksepp, J., and Kiefer, M. (2016b). Individual differences in Affective Neuroscience Personality Scale (ANPS) primary emotional traits and depressive tendencies. Compr. Psychiatry, 73, 136-142.

doi:10.1016/j.comppsych.2016.11.007

Montag, C. \& Davis, K. (2018). Affective Neuroscience Theory and Personality: An Update. Personality Neuroscience, 1, 1-12.

Montag, C., \& Panksepp, J. (2017). Primary emotional systems and personality: An evolutionary perspective. Frontiers in Psychology, 8, 464.

Montag, C., Davis, K. L., Lazarevic, L. B., \& Knezevic, G. (2017). A Serbian version of the ANPS and its link to the five-factor model of personality. Open Psychology, 1, 303-316. https://doi.org/10.1515/psych-2018-0019 Narita, K., Hatta, T., Hirao, K., Mitamura, T., Yama, M., \& Yokode, M. (2017). The validity and reliability in Affective Neuroscience Personality Scale Japanese Edition: An approach to human personality from the Affective Neuroscience [in Japanese]. Japanese Journal of Clinical Psychology, 17(5), 691-702. 
Nielsen, R., Akey, J.M., Jakobsson, M., Pritchard, J.K., Tischkoff, S., \& Willerslev, E.

(2017). Tracing the peopling of the world through genomics. Nature, 541(7637), 302-310.

Doi: $10.1038 /$ nature21347

S. Nishizawa, C. Benkelfat, S. N. Young, M. Leyton, S. Mzengeza, C. de Montigny, P. Blier, and M. Diksic (1997). Differences between males and females in rates of serotonin synthesis in human brain. Proc Natl Acad Sci U S A, 94(10), 5308-5313. doi:10.1073/pnas.94.10.5308

Orri, M., Rouquette, A., Pingault, J. B., Barry, C., Herba, C., Côté, S. M., \& Berthoz, S. (2016). Longitudinal and sex measurement invariance of the affective neuroscience personality scales. Assessment, http://dx.doi.org/10.1177/1073191116656795.

Özkarar-Gradwohl, F.G., Panksepp, J., Içöz, F.J., Çetinkaya, H., Köksal, F., Davis, K.L., \& Scherler, H.N. (2014). The influence of culture on basic affective systems: the comparison of Turkish and American norms on the affective neuroscience personality scales. Culture and Brain, 2 (2), 173-192.

Özkarar-Gradwohl, F.G., Narita, K., Montag, C., Panksepp, J., Davis, K. L., Yama, M., \& Scherler, H. R. (2018). Cross-cultural Affective Neuroscience Personality Comparisons of Japan, Turkey and Germany. Culture and Brain, https://doi.org/10.1007/s40167-018-0074-2 Özkarar-Gradwohl, F.G. (2019). Cross-cultural Affective Neuroscience. Frontiers in Psychology: https://doi.org/10.3389/fpsyg.2019.00794

Pahlavan, F., Mouchiroud, C., Zenasni, F., and Panksepp, J. (2008). French validation of the Affective Neuroscience Personality Scales (ANPS). Rev. Eur. Psychol. Appl., 58, 155-163. doi: 10.1016/j.erap.2007.08.004

Panksepp, J. (1998). Affective neuroscience: The foundations of human and animal emotions. Oxford University Press.

Panksepp, J. (2005). On the embodied neural nature of core emotional affects. Journal of consciousness studies, 12(8-9), 158-184. 
Panksepp, J., \& Biven, L. (2012). The archeology of mind: neuroevolutionary origins of human emotion. New York: Norton.

Panksepp, J., \& Solms, M. (2012). What is neuropsychoanalysis? Clinically relevant studies of the minded brain. Trends in cognitive sciences, 16(1), 6-8.

Panksepp, J., \& Watt, D. (2011). What is basic about basic emotions? Lasting lessons from affective neuroscience. Emotion Review, 3(4), 387-396.

Pascazio, L., Bembich, S., Nardone, I. B., Vecchiet, C., Guarino, G., and Clarici, A. (2015). Validation of the Italian translation of the affective neuroscience personality scales. Psychol. Rep. 116, 97-115. doi: 10.2466/08.09.PR0.116k13w4 Pingault J-B, Falissard B, Cote S, Berthoz S (2012) A New Approach of Personality and Psychiatric Disorders: A Short Version of the Affective Neuroscience Personality Scales. PLoS ONE 7(7), e41489. doi:10.1371/journal.pone.0041489.

Reuter, M., Panksepp, J., Davis, K. L., \& Montag, C. (2017). Die Affective Neuroscience Personality Scales (ANPS) - Testmanual zur deutschsprachigen. Göttingen, Germany: Hogrefe.

Salas, C. E., Radovic, D., Yuen, K. S., Yeates, G. N., Castro, O., \& Turnbull, O. H. (2014). "Opening an emotional dimension in me": Changes in emotional reactivity and emotion regulation in a case of executive impairment after left fronto-parietal damage. Bulletin of the Menninger Clinic, 78(4), 301-334.

Savitz, J., Van Der Merwe, L., \& Ramesar, R. (2008a). Hypomanic, cyclothymic and hostile personality traits in bipolar spectrum illness: a family-based study. Journal of Psychiatric Research, 42(11), 920-929. http://doi.org/10.1016/j.jpsychires.2007.10.011

Savitz, J., Van Der Merwe, L., \& Ramesar, R. (2008b). Personality endophenotypes for bipolar affective disorder: a family-based genetic association analysis. Genes, Brain and Behavior, 7(8), 869-876. http://doi.org/10.1111/j.1601-183X.2008.00426.x 
Schmitt, D. P., Long, A. E., McPhearson, A., O’Brien, K., Remmert, B. \& Shah, S. H. (2017). Personality and gender differences in global perspective. International Journal of Psychology, 52 (S1), 45-56, DOI: 10.1002/ijop.12265

Schmitt, D., Realo, A., Voracek, M. \& Allik, J. (2008). "Why Can't a Man Be More Like a Woman? Sex Differences in Big Five Personality Traits Across 55 Cultures. Journal of Personality and Social Psychology, 94,168-182.

Schore, A. N. (1994). Affect regulation and the origin of the self: The neurobiology of emotional development. Mahwah, NJ: L. Erlbaum Associates.

Sindermann, C., Kendrick, K., Becker, B., Li, M., Li, S., \& Montag, C. (2017). Does growing up in urban compared to rural areas shape primary emotional traits? Behavioral Sciences, 7, 60.

Sindermann, C., Luo, R., Zhao, Z., Li, Q., Li, M., Kendrick, K. M., ... \& Montag, C. (2018). High ANGER and low agreeableness predict vengefulness in German and Chinese participants. Personality and Individual Differences, 121, 184-192.

Solms, M. \& Turnbull, O. (2002). The Brain and The Inner World: An Introduction to the Neuroscience of Subjective Experience. Karnac: London.

Soutscheck, A., Burke, C.J., Beharelle, A.R., Schreiber, R., Weber, S. C., Karipidis, I. I., TenVelden, J., Weber, B., Haker, H., Kalenscher, T., \& Tobler, P. N. (2017). The dopaminergic reward system underpins gender differences in social preferences. Nature Human Behavior. DOI: 10.1038/s41562-017-0226-y

Van Ecke, Y. (2005). Immigration from an attachment perspective. Social Behavior and Personality: An International Journal, 33(5), 467-476.

Volavka, J. (1995). Neurobiology of Violence. Washington, DC: American Psychiatric Press. 
Volf, N. V., \& Privodnova, E. Y. (personal communication). The Russian Standardization of the Affective Neuroscience Personality Scales. State Scientific-Research Institute of Physiology \& Basic Medicine, Lab. of Cognitive Physiology: Novosibirsk, Russian Federation..

Watt, D. F. (2017): Reflections on the neuroscientific legacy of Jaak Panksepp (1943-2017), Neuropsychoanalysis, DOI: 10.1080/15294145.2017.1376549

Yu, C. K.-C. (2016). Can students' dream experiences reflect their performance in public examinations? International Journal of Dream Research, 9 (1), 15-21. 